\title{
Research on Web-based knowledge management system for construction project team
}

\author{
Yun Chen ${ }^{1, ~ a ~, ~ J i a n ~ Z h a o ~}{ }^{2, b}$ \\ ${ }^{1}$ School of Traffic \& Transportation Engineering, Changsha University of Science \& Technology, \\ Hunan Changsha, China \\ ${ }^{2}$ School of Traffic \& Transportation Engineering, Changsha University of Science \& Technology, \\ Hunan Changsha, China \\ a479548805@qq.com, b276736918@qq.com
}

Keywords: Web technology, Construction Project, Knowledge management, Management information system

Abstract. At present, Web technology has fully applied in all walks of life. As a revolutionary development of technology, it will bring immeasurable influence if it is applied to construction project team. Therefore, the use of Web technology for the construction project team knowledge service is imperative. By analyzing the problems existed in the knowledge and information management system of construction project team, and by studying the characteristic of Web-based knowledge management system, this thesis is proposed to combine the Web technology with the common model used for management and information system, as to build the construction project's knowledge and information management system based on the team sources. Sharing on the united information platform, real-time and accurate knowledge could offers more benefit for the team. It is also a more effective way, among participants of various stages, assorted parties and different application systems, to improve the criterion, the design, the construction, and even the entire construction project life cycle, significantly improve the quality and efficiency of project based-on the Web.

\section{Introduction}

As the world stepped into the era of knowledge economy, the demand and application of knowledge are increasingly diverse, personalized, complex and so on. Under this circumstance, the knowledge management of the construction project team is an indispensable part. The knowledge management of construction project team is to create a new environment that make team members to share knowledge, to develop and to utilize knowledge resources to innovate. Compared with the team information management, team knowledge management can be considered as a part which is to be derived from the practice of information management - a new management activities, and the main difference is that the object of information management is the data and information which includes all kinds of original records, yet the object of knowledge management far beyond the scope of data and information, including contained in the minds of team members, tissue and structure of tacit knowledge, and to information as a carrier and in team internal storage, sharing and application of explicit knowledge. However, due to the particularity and complexity of construction projects, there are still some problems in the knowledge management of the construction teams: (1)There is no unified knowledge exchange platform and little communication between the staff of each department. Teammates can not grasp and use all kinds of knowledge resources in time.(2)Much personnel mobility liquid in the Construction industry, work sites scattered and fail to do the analysis and evaluation of the whole project's construction and management process, lack of the effort to arrange document in terms of the skills, the experience and the invisible knowledge, these all force to the difficulty of sharing valuable knowledge. After the end of the project, the team members take their accumulated experience away, then the treasured knowledge becomes vanish or just belong to themselves alone rather than transfer to the freshmen.(3)Some construction companies have their own internal network, but due to the huge amount of knowledge resources, rich content, and the uneven quality, it is difficult for users to quickly 
and accurately obtain useful knowledge. And it may also cannot process the existing knowledge, then the knowledge of re-utilization rate may decrease. And in recent years, with the popularization and the development of the Internet, the supportive and auxiliary function of the Web technology on the construction project team knowledge management has become more and more prominent. Therefore, how to efficiently use the Web technologies for knowledge services and team construction of knowledge management system for construction project team becomes important and significant.

Using the Web technology, the project construction team can integrate the knowledge and file, establish the database and share them in the various departments. Many domestic and foreign scholars have carried on the research, for example: Chalmeta and Grangel ${ }^{[1]}$ proposed a method of making and implementing knowledge management system in any type of project. Pan ${ }^{[2]}$ proposed a framework for knowledge management system based on Web knowledge services, the architecture included 3 levels: basic service layer, application service layer and user service layer so that the knowledge management based on web come true. Zhang ${ }^{[3]}$ combined the Web mining technology with enterprise knowledge management system together. He based on the characteristics of Web data mining then build the construction of the enterprise knowledge management system model. After 2003, there is a new form of Internet application-Web2.0. Some scholars introduce Web2.0 technology into the team knowledge management system. For example: Moria Levy ${ }^{[4]}$ have discussed the concepts and tools of Web2.0 that can be used to enrich knowledge management. Su and Yang ${ }^{[5]}$ designed a Personalized Annotation Management System 2.0 (PAMS2.0). This system mainly used for management. Sharing and collaborative annotation and provides a correlation between users. Huang ${ }^{[6]}$ combined with Web2.0 technology, and proposed a Web2.0-based enterprise collaborative knowledge management system for five layer model and platform architecture that can be for enterprises to carry out knowledge management to provide a real good application environment, and ultimately improve the economic efficiency of enterprises. Wei ${ }^{[7]}$ investigated the mechanism of personal knowledge management, from the knowledge acquisition, knowledge processing, knowledge exchange and sharing three aspects summarizes the Web2.0 platform for personal knowledge management to provide technical support.

Add it all up, using Web technology to the construction of the construction project knowledge management information system, can effectively solve the knowledge management system of tacit knowledge explicitation problems and contribute to the continued development and progress of the construction team. This thesis will be based on the research methods and conclusions of various scholars, using the Web technology, and combined with the characteristics of Web technology team knowledge management, build a Web-based construction project team knowledge management system, to help the team and each department can quickly extract the effective knowledge resources, improve the efficiency of knowledge learning, and enhance the competitiveness of the team.

\section{Characteristics of Web-based knowledge management system}

\section{Convenient and efficient}

From the operation point of view, using the existing knowledge management system for group members may only need to login a browser can edit, inquiry, or share relevant resource information and so on, the operation has become quite convenient and improve the quality and level of the project management. From the storage processing method, the preserve of the traditional knowledge management mostly relying on paper or other physical document, when the age becomes slightly longer, or the number is a little bit larger, it becomes easier to cause the resources damaged and missing, then resulting in the waste of manpower and material resources. And by the way of digital collection can make knowledge learning document well preserved for a long time and do not take much space, do not spend a lot of manpower and material resources to facilitate team members to read, query and use. From the perspective of time, the Web-based knowledge management system can update the latest information resources, and it can be used to share resources and to facilitate the communication between users. 


\section{Simple and practical}

The system interface is simple and easy to understand, the menu is clear, and the operation is basically familiar with Windows, so the team members do not need to training and then quickly learn the use of the system's functions. According to many users' demands, Web-based knowledge management system can be based on the analysis and through accurate and comprehensive application database data standardization to enhance the system user-friendly service level, reduce user's requirements of the system hardware and software, strengthen the knowledge management level of the network, and to accelerate the development of the knowledge management. In addition, the System supports standard TWAIN, ISIS interface, it can be compatible with all scan equipment. The system uses the HTML file as the data exchange, the configuration and the storage standard form, may be the link with all kinds of databases.

\section{Rely on network technology}

The system model based on Web technology, i.e., it rely on network technology, computer software and hardware's processing, data storage, display, extraction and application, and each part once have any kinds of problem, it may difficult to reacquire complete knowledge of the data. In addition, the threat of computer virus, hacker attack, improper operation, information distortion and other factors may cause the loss of knowledge information, and bring irreversible loss.

\section{Analysis of the impact of Web technology on the construction of team knowledge management}

\section{Impact on knowledge acquisition}

With the development of the network and the rise of knowledge management level, it is difficult for the users to obtain the useful information effectively. The cause can be generally divided into two parts: external factors and internal factors. External factors include:(1)The management of construction projects is often lack of awareness of knowledge management, which leads to the knowledge management system in the construction projects difficult to promote and effectively use;2)Knowledge management exists the problem of lacking enough relevant training and few propaganda in the actual work. So many employees do not know how to effectively use the knowledge management;3)The internal project team lost a lot of valuable knowledge naturally due to the regular arrangement by specialized persons. Internal causes include:(1)A huge number of the information resources, a variety of forms, and the management system technological innovations slow Above all could make resources unable to absorb and transform to knowledge;(2)According to the present situation, most team members of the construction projects are satisfied with the existing state, with the limited desire for knowledge. Also, the excitation in the team is not enough is also an important factor.

To build a Web-based knowledge management system can solve the problem of knowledge acquisition of team members. Such as a member upload a technical report, when the report is reasonable organization and input knowledge base, engaged in follow-up project related personnel can through the system get the report, even by the system active push. In addition, team members through Internet technology to achieve real-time interaction and communication, through this process, both the knowledge providers, recipients or the users can enjoy online features retrieval, query, access, so that they are no longer passively accept knowledge, but actively take the initiative to get the required knowledge and ability.

\section{Impact on knowledge sharing}

Awareness and channel of knowledge sharing will affect the construction project team members to learn the knowledge and use efficiency. For example, some of the projects approved by the lack of funds, special funds is to switch to other matters, management attention is insufficient, project members get insufficient excitation and reluctant to share knowledge and experience etc..

Web-based knowledge management can not only enabling team members to finish its duties and tasks, the more important is through the participation to the process of knowledge cycle and improve to create their own knowledge and the ability to organize knowledge and share knowledge. In addition, 
by using the system's blog, Wiki, Email, RSS and other functions, the knowledge sharing would be more efficient and convenient.

\section{Impact on resource reuse}

Web-based management system is convenient which can solve the problem of resource integration and reuse. The use of web technology has changed people for knowledge acquisition and use which is more efficient, full of vitality and new features and changes the use of knowledge, information, technology and other aspects, promote the interaction of information transmission, also accelerated the reuse resources efficiency. By improving the project team's knowledge management's level, Web technology effectively integrating, memorizing and sharing the dynamic knowledge and centralized resources. Reducing the rate of mistakes is also its benefits in this process.

\section{Impact on memory load}

Generally speaking, the construction project team members will handle a large amount of knowledge resources by computer every day, make these resources into the computer, if not be classified storage, only relying on human brain will inevitably lead to subsequent index, extraction, integration, increase the difficulty of the procedure, and this part of the resources cannot effectively turn to formation of knowledge, experience for people to use, furthermore it may also spent a lot of manpower and material resources and resources caused by unreasonable use.

The Web-based technology on team knowledge management can effectively avoid those problems and can also to satisfied the current construction projects more and more complex requirements. Through no disk network, it is necessary to use the network server to achieve the work tasks. In addition, the recent general technology - cloud storage technology is another Internet storage mode which in usually stored data by the third party escrow multiple virtual servers. This service is accessed through the Web API or by the Web user interface. No matter what kind of the storage technology, they all based on Web technology to meet the people's increasing needs and trying to help the brain to solve the reduced memory load and better learn the knowledge resources utilization.

\section{Build system}

\section{Web Technology}

Web is a product of Internet development, and it is a typical distributed application structure. It performed by three forms: Hypertext、Hypermedia、HTTP. Every information exchange in Web application involves both the client and the server. Therefore, the Web technology can be broadly divided into two categories: client and server.

Web client

Generally, the software called the Web client which will be the Web client, its main task is to display information content. The main technology of Web client: HTML、Java Applets、Script program、 CSS、DHTML、Plug-in technology and VRML。Basic work flow: users click the hyperlink or enter the address in the browser, the browser will convert the information into a standard HTTP request sent to the Web server. When the Web server receives the HTTP request, according to the request to find the required information resources, then the Web server will sends back the HTTP response to the browser, the browser receives the HTML document after the response. Some common client is the Web browser, such as IE, Firefox, Chrome, etc..

Web server

Web server is about to use the local information with hypertext organization, for the user to search and browse information on the Internet to provide services. The main technologies include CGI、PHP、 ASP、ASP.NET、Servlet and JSP technology. The user requests a resource to the Web server through the Web browser. When the Web server receives the request, it will search the resource for the user, and then returns the resource to the Web browser. Common Web server is a network operating system, Web service components, etc..In essence, the Web server is actually a software system. 


\section{The information system model of Web-based construction project team knowledge management}

Overall structure

With the development of Web technology, the traditional C/S structs has been unable to meet the requirements of globalization, information sharing and storage. So, the Browser/Server structs has been generated, as shown in Fig. 1. B/S structs is a change or improvement to the application of C/S structs. In this structs, the user interface is achieved through the browser, that is, the users can send applications to the browser by the form of HTML, the browser to the Web server to send access request. After the Web server connect the browser, it will communicate with the database and achieved results immediately, and then the results of the database returned to the browser. The biggest advantage of this structs is that the client uses the browser which is not only convenient for the user to use, but it makes the customer machine does not exist the problem of installation and maintenance. Software development and maintenance work is transferred to the Web server.

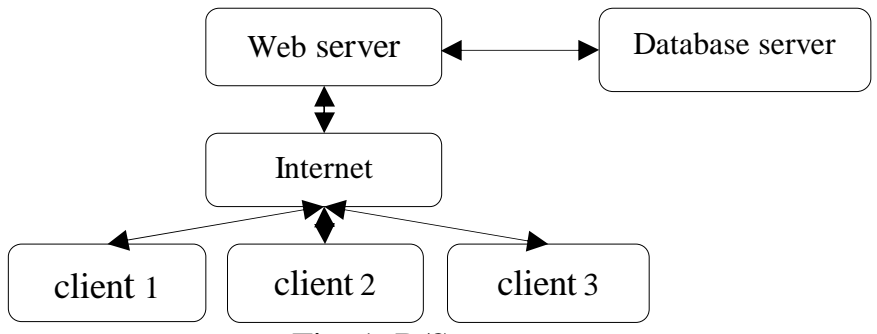

Fig. $1 \mathrm{~B} / \mathrm{S}$ structs

System model establishment

Under the fully consideration of the influence factors of Web-based construction team knowledge sharing, we set up a sharing platform based on the web for construction project team knowledge management. The platform mainly consists of four levels: resource construction layer, basic service layer, application service layer, user service layer. Its basic frame is shown in Fig. 2.

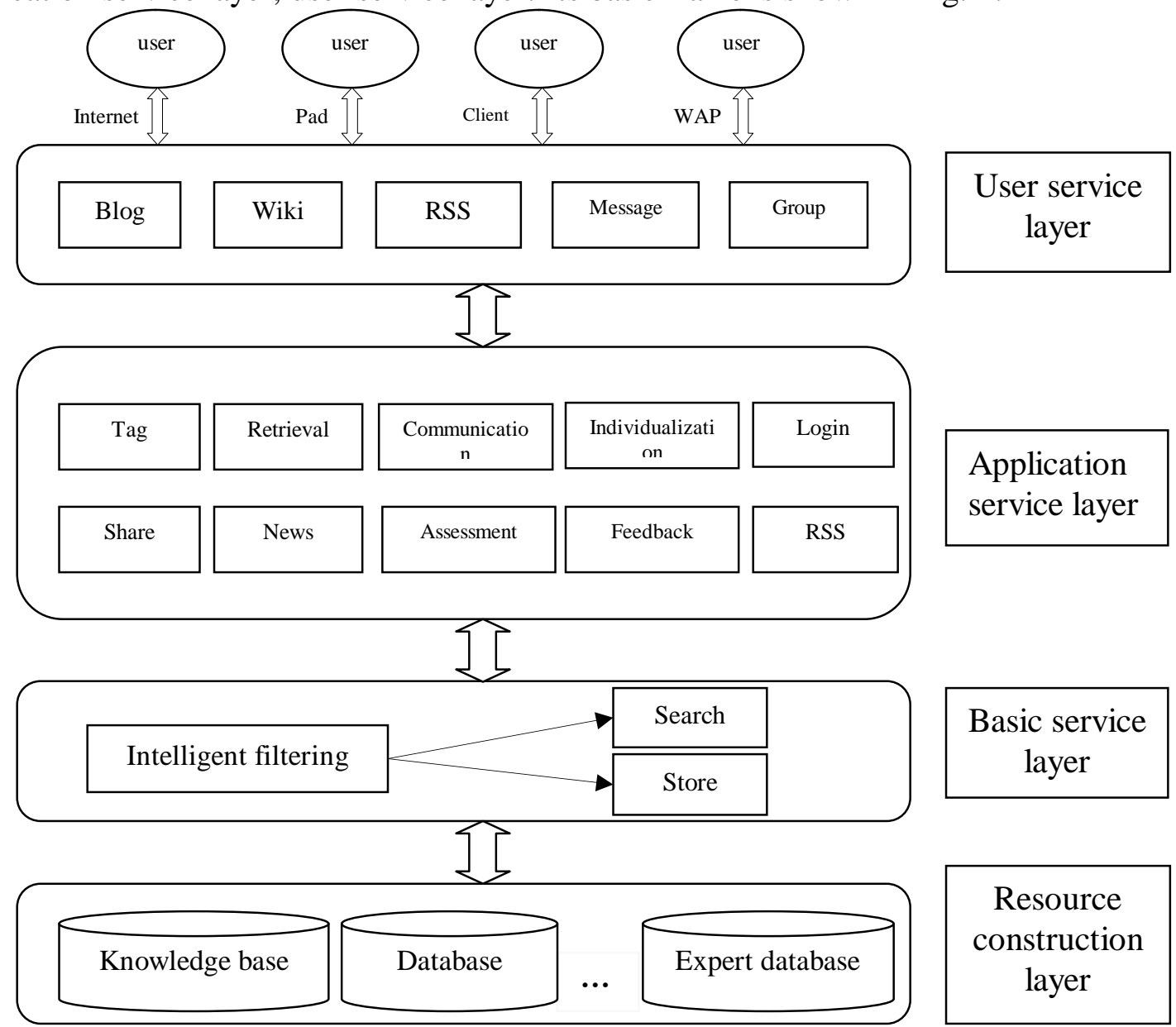

Fig. 2 Basic framework of system model 


\section{1) Resource construction layer}

Resource construction layer is the first layer or the bottom layer, it is the construction team knowledge storage layer and also the team's knowledge management system infrastructure. This layer consists of knowledge base which is structured (knowledge base, database, log library, etc.) and unstructured (file system, information resources and experience in the field of knowledge of experts), and also contains the successful practical knowledge of historical accumulation, the dominant knowledge and the tacit knowledge in the human brain. The team knowledge base is used to store the knowledge of the team after a structured process; Database which is stored the construction team in the workflow data and metadata; Expert database which is mainly used for storing various construction fields and different direction of expert information and decided the project team in the evaluation of selection expert level and boundary, experts can put knowledge into the team's knowledge base through a unified way.

In addition, this layer also includes computer network communication system, it establishes the foundation of computer networking. For example, in the infrastructure, it support for mainstream servers, networks and other hardware systems and Windows/Linux/UNIX operating system, etc.. Resource construction layer is the foundation of the whole construction team knowledge management system, its function is to store and share the knowledge of the team to provide the resources service and technical support for the upper system structure.

2) Basic service layer

Basic service layer is the middle layer which is the core part of the whole knowledge management system. It is responsible for the data and the knowledge acquisition of the front office and back office. By classifying and filtering knowledge, and by means of word frequency analysis, retrieval and organization, to share and transfer knowledge. This layer mainly provides two services: knowledge search and knowledge storage. Knowledge search refers to the project team members or users to submit the information that needed to retrieve. The platform provides an open API based service which will intergrate applications of different members with their diverse needs, and build a resource layer in the knowledge base matching then finally provide a member or user needs accurate knowledge. Knowledge storage is an important service for team resource update, after an intelligent filtering and structuring of the information of a member or a user, finding user's logs and behavior and deposited to team knowledge base then provide a support for the application service layer's RSS push service.

3) Application service layer

Application service layer is a senior layer. This layer is based on the basic service layer and the requirement of the construction team knowledge management. In order to make full use of knowledge resources, team members or user could defined some alternative, relatively independent of the service module to achieve the distribution of knowledge, exchange, sharing, integration and internalization. Specific services include: Network tags services, push services, knowledge exchange services, knowledge recommendation services, single point landing, resource retrieval, browsing and personalization, etc.. These services are encapsulated into a unified application service and released to the construction team ESB, through the WCF technology to communicate with different clients.

4) User service layer

The user service layer or the highest level is responsible for the interaction with the user interface and provide services interface. Construction team members or users can access through a variety of terminal and access platform such as Internet $\mathrm{Pad} 、$ WAP or professional client. It integrates the lower level into a user friendly interface, and gives users a different authority which is entered by the unified entrance. Its function is to give the users specific knowledge of the classification, communication, sharing and application. Specifically, the layers including blog, wiki, RSS, discussion groups and information exchange platform which will makes the construction team members or users can access their own information and knowledge. 


\section{System function module}

Web-based knowledge management system's important applications include: blog, wiki, discussion groups and public information platform, and for the construction project team the main use of this is the front of three application. Blog is for technical staff to record their own experience during the daily construction experience, and make the individual's knowledge into explicit expression. Wiki is a collaborative writing system, it can effectively gather the wisdom of all the technical staff and management, such as for a term, a rule, a check report, a record of the construction of repeated modification and improvement, and ultimately to achieve a more consistent view. Discussion groups will collect network resources by the technical staff, and to be efficient and convenient to share their knowledge, it can saving a large part of the repetitive thinking time and mechanical labor. According to the current development trend of the construction project team knowledge management, the knowledge management system can be divided into six functional modules: knowledge classification module、 knowledge publishing module、 knowledge retrieval module、 knowledge collaboration module、knowledge subscription module、 message management module.

Knowledge classification module

Knowledge classification module is mainly to realize the classification management, knowledge content editing and other functions. The administrator can maintain and manage them, as shown in Fig. 3. By clicking on a list of knowledge in a certain category, you can manage the relevant entries.

\section{建设项目团队知识管理信息系统}

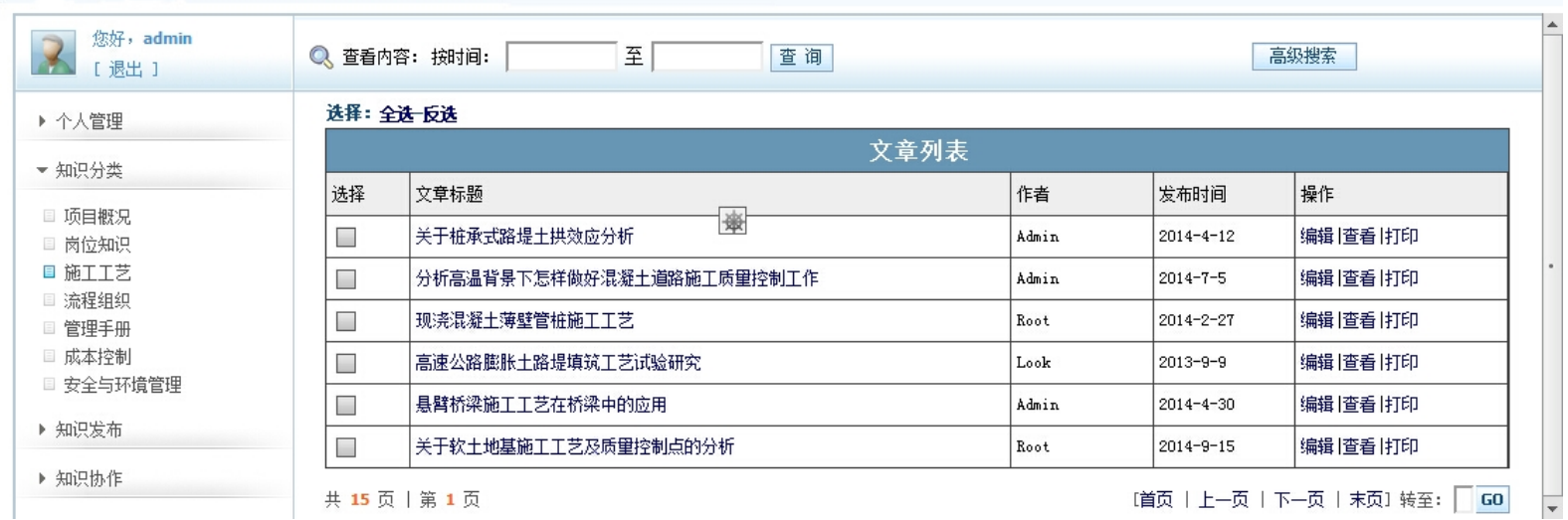

Knowledge publishing module

Fig. 3 Knowledge classification module

In the knowledge publishing module, the users can input the knowledge into the knowledge base by the template file, as shown in Fig. 4. When the users input the knowledge they need to enter the title, abstract, keywords and other basic information, and select the appropriate classification and labeling. At the same time, the system provides the content of knowledge editing tools, users can easily enter the knowledge content or modify. In addition, users can also upload the relevant attachments and finally store the knowledge to the knowledge base.

\section{建设项目团队知识管理信息系统}

\begin{tabular}{|c|}
\hline \begin{tabular}{|l|l} 
您好, admin \\
[退出 ]
\end{tabular} \\
\hline - 个人管理 \\
\hline - 知识分类 \\
\hline 一知识发布 \\
\hline $\begin{array}{l}\square \text { 知识录入 } \\
\square \text { 知识 } \\
\square \text { 我发布的知识 }\end{array}$ \\
\hline 1知识协作 \\
\hline - 知识订阅 \\
\hline D消息管理 \\
\hline
\end{tabular}

知识添加页面

- 㳵加识
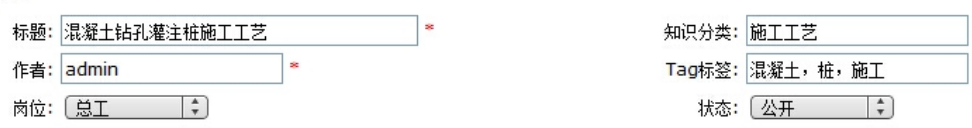

内容:

钻孔灌注桩的施工, 因其所选护壁形成的不同, 有泥将护壁方式法和全套管施工法两种。

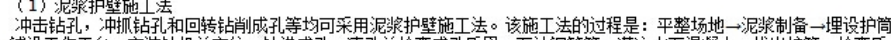
重。

Fig. 4 Knowledge publishing module 
Knowledge retrieval module

Knowledge retrieval module is an important part of the system which is convenient for users to find the knowledge they need quickly and accurately. This module provides a unified knowledge search for the users to search for a variety of different knowledge within the entire project team. Users can choose the scope of the implementation of the search. This module support for a variety of retrieval methods, such as title search, content retrieval or Tag-based search, as shown in Fig. 5.

\section{Q 查看内容: 按标题: $\quad$ 查 询 高级搜索}

Fig. 5 Knowledge retrieval module

Knowledge collaboration module

Knowledge collaboration module provides a working area of knowledge sharing and collaboration for project team members. Users can submit technical documents in the wiki knowledge and they can also publish project announcements and discussion questions, other users can view knowledge as well as its version of history, and they can comment or edit this knowledge. As it shown in Fig. 6, the users can view the project information and communicate with the project team members through the "project I participated" and "project members".

\section{建设项目团队知识管理信息系统}

速

\begin{tabular}{|l|l|}
\hline 7 您好, admin \\
[退出 ]
\end{tabular}

Q日录: 问题讨论) 查间高级提索

\begin{tabular}{|c|c|c|c|c|c|}
\hline \multicolumn{6}{|c|}{ 问题讨论列表 } \\
\hline 序列 & 标题 & 发布日期 & 状态 & 作者 & 详情 \\
\hline 1 & 箱梁翌向预应力筋和㮨向预应力筋设计 & 2014-10-5 & 公开 & Root & 查着 | 评论 | 收藏 \\
\hline 2 & 讨论波浪对桥梁较台的影响, 并确定不同条件下波浪对桥梁㜞台的作用力 & 2013-3-26 & 公开 & Wei & 查着 | 评论 | 收藏 \\
\hline 3 & 关于城市道路中减速带的设置问题 & 2014-3-8 & 公开 & admin & 查看 | 评论 | 收藏 \\
\hline 4 & 工期纠纷与工期索湆的相关问题 & 2014-7-12 & 锁定 & admin & 查看 | 评论 | 收藏 \\
\hline 5 & 道路刚改柔|日水溊括路面碎石化施工 & 2013-5-16 & 公开 & Root & 查看 | 评论 | 收藏 \\
\hline 6 & 关于随道祄枷结构设计中, 系统鞇杆的计算问题 & 2014-11-9 & 公开 & Fang & 查着 | 评论 | 收藏 \\
\hline
\end{tabular}

Knowledge subscription module

The goal of construction project team knowledge management is to achieve the appropriate time to pass to the appropriate person to help them in decision-making. Knowledge is acquired through knowledge sharing platform, and then classified according to the requirements. After the process of indexing, publishing and other functions, it is ready for the right person to visit in the appropriate time. Knowledge push service is one of the effective ways to achieve knowledge transfer, as shown in Fig. 7. This system uses RSS to provide users with convenient personalized knowledge push service so that users can pay attention to their knowledge and information which they wanted to.

\section{建设项目团队知识管理信息系统}

\begin{tabular}{|c|c|c|}
\hline $\begin{array}{l}\text { 您好, admin } \\
\text { [ 退出 ] }\end{array}$ & Q内容: & 查询 \\
\hline 1 个人管理 & & 知识资讯： \\
\hline - 知识分类 & & 项目团队动态活动通知 公告信息 行业资讯 \\
\hline > 知识发布 & & 知识专家: \\
\hline - 知识协作 & & 项目经理 项目总工工程部部长 质检部部长成本部部长 \\
\hline 一知识订阅 & & 案例分析： \\
\hline $\begin{array}{l}\text { 我的订阅 } \\
\text { 口订阅知识 }\end{array}$ & & 工程实例造价案例安全事故处理 \\
\hline ・消息管理 & & \\
\hline
\end{tabular}

Fig. 7 Knowledge subscription module 
Message management module

Message management module provides the following four functions: send message, receive message, send information to view, message list. In order to achieve the purpose of project team knowledge sharing and transfer, the members of the project team can be sent to a specific recipient by the module and also be able to receive messages from a specific member of the real time.

\section{建设项目团队知识管理信息系统}

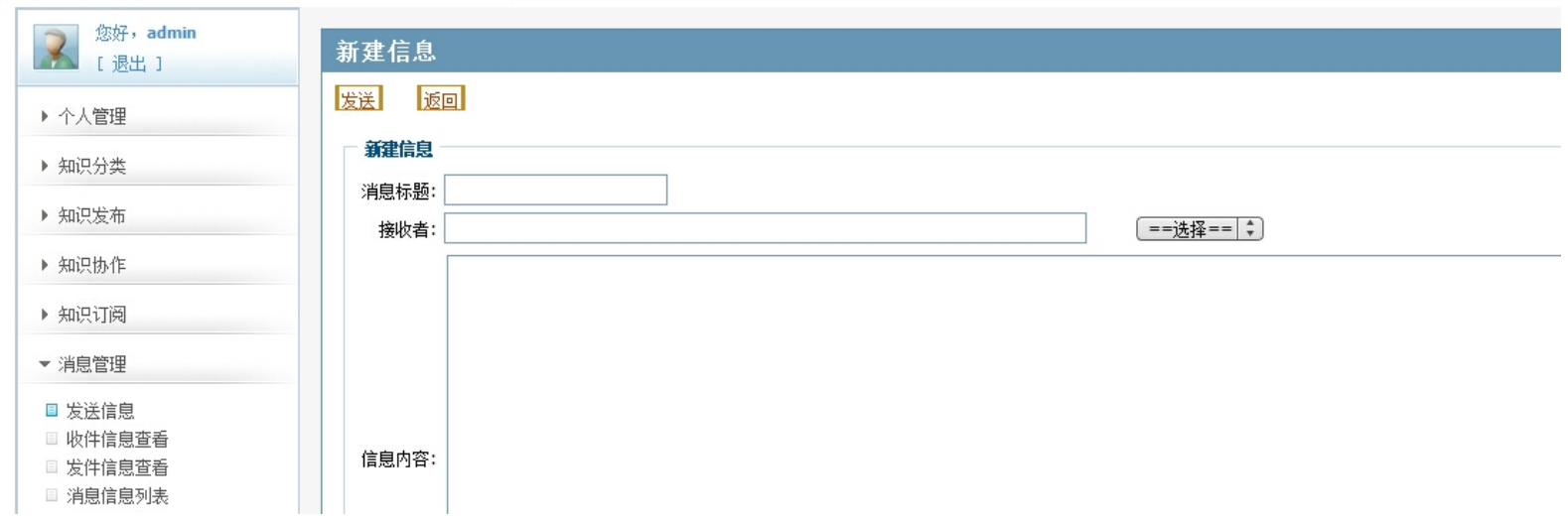

Fig. 8 Message management module

\section{Key technology of the system}

Knowledge representation

The Web-based knowledge management system's source of knowledge is diverse, but the underlying model of the database is unified. The HTML format which is structured and easy to be edited provide a variety forms of knowledge and it also provides a unified data source.

Knowledge integration mode

Web-based knowledge management system's most core part is a strong communication, cooperation and sharing of the functions of the integrated service platform. This system introduces four kinds of typical Web elements: Blog, RSS, Wiki, BBS, and then use the SOA technology to integrate. Because of the mining of tacit knowledge, it is needed to make use of HTML technology, label technology, mining technology and other technical means to make tacit knowledge into explicit knowledge.

Knowledge storage mode

The system provides expert information database, equipment database, technology database, accident case library.The storage of these knowledge bases is after the evaluation and recommendation of knowledge, and it need special knowledge base management staff and technical experts' examination.

In summary, this thesis establishes the construction project team knowledge management system by using the B/S structs, it has established four layer model and five function modules. The system can integrate all kinds of knowledge resources, such as knowledge of owner, designers, suppliers, contractors, internal OA system and expert database system into a whole organization. It can make the construction team members, as well as the external users be more convenient, fast and accurate accept their required knowledge, so as to achieve the full sharing of knowledge resources goal.

\section{Conclusions}

In this thesis, by analyzing the existing construction project team knowledge learning and the characteristics of knowledge management, and with the help of web technology's powerful storage, integration and sharing ability, we build an efficient and integrated construction project team knowledge management system model. By using the function of the system model, the construction team can make tacit knowledge into explicit knowledge and make knowledge's integration and sharing become more effective. Besides, team knowledge management will be more flexible, extensible and 
also can be recycled. These make the Web-based knowledge management system can better adapt to the development of construction projects, and therefore provide more quality services.

\section{References}

[1] Chalmeta R, Granger R. Methodology for the implementation of knowledge management systems [J] .Journal of the American Society for Information Science and Technology, 2008,59 (5): $742-755$.

Knowledge management system architecture [2] Pan Xing, Wang Jun Liu Lu and other knowledge based Web services [J] Computer Integrated Manufacturing Systems, 2006, 12 (8): 1293-1299.

[3] Zhang Xiaojing, Yao Jiayi Model of Enterprise Knowledge Management System Framework Based on Web Data Mining [J] Inner Mongolia Science Technology and Economy, 2009, (19): 11-13.

[4] Moria Levy, WEB 2.0 implications on knowledge management [J] .Journal of Knowledge Management, 2009,13 (I): 120-134.

[5] SU ADDISON Y S; YANG STEPHEN J H; WUY H.A Web 2.0-based collaborative annotation system for enhancing knowledge sharing in collaborative learning environments $[\mathrm{J}]$.Computers and Education, 2010,55 (02): 752-766.

[6] Huang Zhiyong. Web2.0-based Enterprise Collaborative Knowledge Management System [D]. Master's degree thesis, Wuhan University of Technology, 2011.

[7] Wei Bailian, Zheng Jianming study personal knowledge management Web2.0 [J]. Based on modern intelligence, 2010,05: 170-173. 